\title{
Impact of Contrast-Induced Nephropathy on Long- Term Renal Function after Coronary Angiography and Contrast-Enhanced Computed Tomography
}

Hidekazu Moriya ( $\nabla$ h_moriya@shonankamakura.or.jp )

Shonan Kamakura General Hospital

Yasuhiro Mochida

Shonan Kamakura General Hospital

Kunihiro Ishioka

Shonan Kamakura General Hospital

Machiko Oka

Shonan Kamakura General Hospital

Kyoko Maesato

Shonan Kamakura General Hospital

Mizuki Yamano

Shonan Kamakura General Hospital

Hiroyuki Suzuki

Shonan Kamakura General Hospital

Takayasu Ohtake

Shonan Kamakura General Hospital

Sumi Hidaka

Shonan Kamakura General Hospital

Shuzo Kobayashi

Shonan Kamakura General Hospital

\section{Research Article}

Keywords: contrast media, contrast-induced nephropathy, prognosis, chronic kidney disease

Posted Date: January 24th, 2022

DOI: https://doi.org/10.21203/rs.3.rs-1223161/v1

License: (1) (1) This work is licensed under a Creative Commons Attribution 4.0 International License.

Read Full License 
1 Impact of contrast-induced nephropathy on long-term renal

2 function after coronary angiography and contrast-enhanced

3 computed tomography

4

5 Running head: CIN and long-term renal function in CAG/CECT

6

7 Hidekazu Moriya1), Yasuhiro Mochida ${ }^{1)}$, Kunihiro Ishioka1), Machiko Oka1), Kyoko

8 Maesato ${ }^{1)}$, Mizuki Yamano1), Hiroyuki Suzuki1), Takayasu Ohtake1), Sumi Hidaka1),

9 and Shuzo Kobayashi ${ }^{1)}$

10

11 Kidney Disease and Transplant Center, Shonan Kamakura General Hospital,

12 Kanagawa, Japan ${ }^{1)}$

13

14

15

Corresponding author:

16 Hidekazu Moriya

17 Email: $\underline{h \text { moriya@shonankamakura.or.jp }}$

18 Tel: +81-467-46-1717 Fax: +81-467-45-9792

19 Address: Kidney Disease and Transplant Center, Shonan Kamakura General

20 Hospital, 1370-1 Okamoto, Kamakura, Kanagawa, Japan 247-8533

21

22 Key Word: contrast media, contrast-induced nephropathy, prognosis, chronic kidney 23 disease 


\section{Abstract}

\section{Background}

3 It remains unclear whether contrast-induced nephropathy $(\mathrm{CIN})$ has a prognostic

4 impact on subsequent renal dysfunction and whether deteriorating renal function is a

5 risk factor for CIN. This study aimed to evaluate the occurrence of CIN in patients

6 with pre-existing renal dysfunction and investigate the long-term effects of worsening

7 renal function after coronary angiography or contrast-enhanced computed

8 tomography (CT). The prognostic factors of worsening renal dysfunction were also

9 analyzed.

\section{Methods}

11 This was a prospective cohort study of patients at risk for CIN, defined as an

12 estimated glomerular filtration rate (eGFR) $<60 \mathrm{~mL} / \mathrm{min} / 1.73 \mathrm{~m}^{2}$ on coronary

13 angiography or eGFR $<45 \mathrm{~mL} / \mathrm{min} / 1.73 \mathrm{~m}^{2}$ on contrast-enhanced CT. Serum

14 creatinine levels and the 2-year prognosis were evaluated. CIN was defined as an

15 increase in serum creatinine level by more than $0.5 \mathrm{mg} / \mathrm{dL}$ or a $25 \%$ increase from

16 the previous value within 72 hours after contrast administration. The primary endpoint 
1 was the proportion of patients who had serum $\mathrm{Cr}$ doubling or induction of dialysis

2 within 2 years according to CIN occurrence.

\section{Results}

4 Of the 410 patients, 19 patients developed CIN (8/142 patients on coronary

5 angiography and 11/268 patients on contrast-enhanced CT), and 38 patients had

6 worsened renal function (21/142 patients on coronary angiography and 17/268

7 patients on contrast-enhanced CT). CIN was not associated with worsening renal

8 function at 2 years. Analysis by renal function at the time of coronary angiography or

9 contrast-enhanced CT (i.e., eGFR $\geq 30 \mathrm{ml} / \mathrm{min} / 1.73 \mathrm{~m}^{2}$ and eGFR $\leq 1.73 \mathrm{~m}^{2}$ ) found no

10 between-group difference in the occurrence of CIN.

\section{Conclusions}

12 CIN is not a prognostic risk factor for the long-term of chronic kidney disease after coronary angiography or contrast-enhanced CT. Pre-existing renal dysfunction is

14 also not a risk factor for CIN, even if the eGFR is $<30 \mathrm{ml} / \mathrm{min} / 1.73 \mathrm{~m}^{2}$. 


\section{Introduction}

2 The use of contrast media increases the risk of worsened renal function in patients

3 with pre-existing renal dysfunction. An estimated glomerular filtration rate (eGFR)

$4<60 \mathrm{~mL} / \mathrm{min} / 1.73 \mathrm{~m}^{2}$ on coronary angiography eGFR $<30 \mathrm{~mL} / \mathrm{min} / 1.73 \mathrm{~m}^{2}$ on

5 transvenous contrast-enhanced CT is associated with the risk of contrast-induced

6 nephropathy (CIN). However, data on worsening renal function as a long-term

7 prognosis of CIN are limited. The risk of acute kidney injury after contrast media

8 administration is also influenced by patient- and procedure-related factors. Clinical

9 factors that increase the risk for $\mathrm{CIN}$ include pre-existing renal dysfunction, diabetes

10 mellitus in the setting of underlying renal impairment, advanced congestive heart

11 failure, intravascular volume depletion, administration of large volumes of contrast

12 media, and the use of high-osmolar contrast media [1-5].

13 In 2018, the Japanese Society of Nephrology, the Japanese Society of Radiology,

14 and the Japanese Society of Cardiology jointly developed the "Guideline on the use

15 of iodinated contrast media in patients with kidney disease" [6]. The guidelines

16 include the definition of $\mathrm{CIN}$, patient assessment, and the occurrence of $\mathrm{CIN}$ on 
1 coronary angiography and contrast-enhanced CT. The guidelines are aimed to

2 prevent the occurrence of contrast media-induced renal dysfunction, standardize

3 renal function assessment methods for patients who use contrast media, and

4 optimize the use of contrast media. However, the guidelines do not clearly state the

5 standardization of renal function assessment after contrast testing, evaluation of

6 long-term effects on renal function, and differentiation from other complications that

7 affect renal function, such as cholesterol crystal embolism. The impact of contrast

8 tests on renal function is important for patients with chronic kidney disease. As such,

9 the long-term decline in renal function and development of other complications due to

10 contrast tests should be carefully considered.

11 This study aimed to evaluate the occurrence of $\mathrm{CIN}$ in patients with renal dysfunction

12 who underwent contrast media test and treatment (coronary angiography or contrast-

13 enhanced CT) and the long-term effects of contrast media testing on renal function

14 after. Further, we examined the prognostic factors related to worsening renal

15 function. 


\section{Materials and Methods}

$2 \quad$ Study design and patients

3 We prospectively studied the changes in renal function after coronary angiography or

4 contrast-enhanced computed tomography (CT) performed between April 2014 and

5 March 2017. Patients at risk for CIN, defined as an eGFR $<60 \mathrm{~mL} / \mathrm{min} / 1.73 \mathrm{~m}^{2}$ on

6 coronary angiography or an eGFR $<45 \mathrm{~mL} / \mathrm{min} / 1.73 \mathrm{~m}^{2}$ contrast-enhanced CT, were

7 eligible. The inclusion criterion was age at least 20 years. The exclusion criteria were

8 as follows: 1) allergy to contrast media, 2) renal replacement therapy, 3) pregnancy, 4)

9 severe liver dysfunction, and 5) hyperthyroidism. Serum saline loading was performed

10 at the discretion of the attending physician before and after administration of contrast

11 media.

12 Pre-study assessments included patient background (age, sex, presence of diabetes, cardiovascular disease, and smoking), examination conditions (amount of contrast

14 medium, volume of supplemental fluid), and history of drug use (diuretics, RAS

15 inhibitors). The blood tests included evaluation of renal function before the contrast 
1 test and at 3 days, 1 month, 3 months, 1 year, and 2 years after coronary

2 angiography or contrast-enhanced CT.

$4 \quad$ Variable definitions and study end points

$5 \mathrm{CIN}$ was defined as an increase in serum creatinine level by more than $0.5 \mathrm{mg} / \mathrm{dL}$ or

6 a $25 \%$ increase from the previous value within 72 hours after iodine contrast

7 administration according to the above guideline [1]. Renal cholesterol crystal

8 embolism was defined as (1) cholesterol crystals on renal biopsy or (2) presence of

9 blue toe and rapidly progressive renal dysfunction, reticular plaques in the lower

10 limbs, or eosinophilia $(>500 / \mu \mathrm{L})$.

11 To evaluate the long-term prognosis of renal function after the occurrence of $\mathrm{CIN}$, the

12 primary endpoint was set as worsening renal function, defined as a doubling of

13 serum creatinine or initiation of dialysis at 2 years. The secondary endpoints were the

14 presence of renal cholesterol crystal embolism, death, and an exploratory evaluation

15 of risk factors related to serum creatinine doubling or induction of dialysis at 2 years. 
$1 \quad$ Statistical analyses

2 Our primary analyses were based on assessing the occurrence of CIN and the

3 associations of $\mathrm{CIN}$ with outcomes at 2 years in the overall study population, and

4 among subgroups by baseline renal function and comorbidities. Th patients were

5 stratified by comorbidities, and their characteristics were compared using analysis of

6 variance or chi-square tests for categorical variables. Bonferroni analysis was used

7 to evaluate the significance of differences among the groups. All statistical analyses

8 were performed using SPSS statistical software.

9

10 Results

11 Patient characteristics

12 Of the 162 patients who underwent coronary angiography, 142 patients were

13 identified to be at risk for CIN and were followed up for 2 years. Meanwhile, of the

14283 patients who underwent contrast-enhanced CT examination, 268 were identified

15 to be at risk for $\mathrm{CIN}$ and were followed up for 2 years. Thus, 410 patients were

16 included in the analysis. Among them, 19 patients (4.6\%; 8/142 (5.6\%) patients in the 
1 coronary angiography group and 11/268 patients in the contrast-enhanced CT group)

2 developed $\mathrm{CIN}$ within 3 days after the administration of contrast media. There were

$3 \quad 38 / 410(9.3 \%)$ patients who had worsening renal function at 2 years. With respect to

4 the long-term prognosis of CIN, 4/19 (21.1\%) patients who developed CIN had

5 worsening of renal function thereafter ( 2 and 2 patients in the coronary angiography

6 and contrast-enhanced CT groups, respectively). The patient characteristics in each

7 group are detailed below.

8

$9 \quad$ Coronary angiography group

10 The mean patient age was 71.6 years, and the mean serum creatinine and eGFR at

11 the time of enrollment were $1.96 \mathrm{mg} / \mathrm{dl}$ and $30.1 \mathrm{ml} / \mathrm{min} / 1.73 \mathrm{~m}^{2}$, respectively. There

12 were 48 patients (33.8\%) with diabetes mellitus, and 45 patients (31.7\%) received

13 serum saline infusion before and after the examination. The mean volume of the

14 contrast medium used was $35 \mathrm{ml}$ (Table 1).

15 The mean serum creatinine level 3 days after angiography was $2.00 \pm 0.66 \mathrm{mg} / \mathrm{dl}$,

16 which was not significantly elevated than that at baseline. After 2 years, 21 patients 
$1 \quad(14.8 \%)$ had serum $\mathrm{Cr}$ doubling or initiated dialysis, but only 1 patient developed

2 cholesterol crystal embolism. Fifteen patients died, and eleven of them died due to

3 cardiovascular disease (Table 2).

4 Analysis according to renal function at the time of coronary angiography (eGFR $\geq 30$

$5 \mathrm{ml} / \mathrm{min} / 1.73 \mathrm{~m}^{2}$ and eGFR of $\leq 1.73 \mathrm{~m}^{2}$ ) showed no significant difference in the

6 occurrence of CIN (Table 3A). There was also no significant association between the

7 occurrence of $\mathrm{CIN}$ and worsening of renal function at 2 years (Table $4 \mathrm{~A})$. The factors

8 related to the worsening of renal function at 2 years were the presence of

9 cardiovascular disease (i.e., the presence of myocardial infarction, angina pectoris,

10 and chronic heart failure) and pre-existing renal dysfunction at the time of coronary

11 angiography(Table 5).

13 Contrast-enhanced CT group

14 The mean patient age was 74.3 years, and the mean serum creatinine and eGFR at

15 enrollment were $1.72 \mathrm{mg} / \mathrm{dl}$ and $35.6 \mathrm{ml} / \mathrm{min} / 1.73 \mathrm{~m}^{2}$, respectively. Diabetes mellitus

16 was present in 76 patients (28.4\%), and 47 patients (17.5\%) received serum saline 
1 infusion before and after the examination. The mean volume of the contrast medium

2 used was $82 \mathrm{ml}$ (Table 6).

3 The serum creatinine level 3 days after contrast-enhanced CT was $1.67 \pm 0.58 \mathrm{mg} / \mathrm{dl}$,

4 which was not significantly elevated than that at baseline. At 2 years after the

5 procedure, 17 patients had serum $\mathrm{Cr}$ doubling or initiated dialysis, but no patient had

6 cholesterol crystal embolism. Nineteen patients died, and most deaths were due to

7 malignancy or infection (Table 2).

8 Analysis by renal function at the time of contrast-enhanced CT (i.e., eGFR $\geq 30$

$9 \mathrm{ml} / \mathrm{min} / 1.73 \mathrm{~m}^{2}$ and eGFR $\leq 1.73 \mathrm{~m}^{2}$ ) showed no difference in the occurrence of CIN

10 (Table 3B). There was no significant association between the occurrence of $\mathrm{CIN}$ and

11 the 2-year prognosis of renal function, similar in the coronary angiography group

12 (Table 4B). The factors associated with the 2-year prognosis of renal function were

13 age and diabetes mellitus, in addition to pre-existing renal dysfunction (Table 7).

\section{Discussion}


1 In the past, it was considered that the use of contrast media had a risk of worsening

2 renal function. However, in the present study, $\mathrm{CIN}$ is not a prognostic risk factor for

3 the long-term of chronic kidney disease after coronary angiography or contrast-

4 enhanced CT. Pre-existing renal dysfunction is also not a risk factor for CIN, even if

5 the eGFR is $<30 \mathrm{ml} / \mathrm{min} / 1.73 \mathrm{~m}^{2}$.

6 Contrast-induced acute kidney injury is characterized by a decrease in renal function

7 that occurs within 3 days after the intravascular administration of an iodinated

8 contrast material. After contrast media exposure, vasoconstriction leads to intense,

9 but transient reduction in renal blood flow, direct toxicity to the renal tubular

10 epithelium, and tubular obstruction by protein precipitates [7]. It is generally believed

11 that arteriography is associated with a higher risk of contrast-induced acute kidney

12 injury than venography (e.g., contrast-enhanced CT) owing to the delivery of a more concentrated contrast material to the kidneys with angiography and the higher overall

14 risk profile of patients requiring such procedures [8].

15 The 2012 Japanese guidelines on the use of contrast media initially stipulated that a contrast-enhanced CT scan was associated with a risk of CIN in patients with eGFR 
$1<45 \mathrm{ml} / \mathrm{min} / 1.73 \mathrm{~m}^{2}$. However, the revised guidelines in 2018 lowered the risk level to

2 eGFR $<30 \mathrm{ml} / \mathrm{min} / 1.73 \mathrm{~m}^{2}[6]$. Several studies have also reported that there is no risk

3 of $\mathrm{CIN}$ even in patients with eGFR $<30 \mathrm{ml} / \mathrm{min} / 1.73 \mathrm{~m}^{2}$ [9-12]. Meanwhile, the risk of

4 CIN remains high in coronary angiography. In this study, the risk of CIN was not

5 significantly related to renal function at the time of angiography, even in patients with

6 eGFR $<30 \mathrm{ml} / \mathrm{min} / 1.73 \mathrm{~m}^{2}$. There was also no risk of CIN in contrast-enhanced CT

7 scan in patients with eGFR $<30 \mathrm{ml} / \mathrm{min} / 1.73 \mathrm{~m}^{2}$.

8 Recent studies have suggested that the risk of acute kidney injury due to contrast

9 material is overestimated [13-17]. The rate of CIN in the present study is lower (5.6\%

10 for arterial contrast and $4.1 \%$ for venous contrast) than in previous studies despite

11 that we included only patients with pre-existing renal dysfunction. Contrast media-

12 induced renal dysfunction in both coronary angiography and contrast-enhanced CT is

13 a risk factor for long-term renal dysfunction. However, this study found that the

14 occurrence of $\mathrm{CIN}$ was not significantly related to pre-existing renal dysfunction on

15 either coronary angiography or contrast-enhanced CT. Furthermore, even if CIN

16 occurs, it is not associated with the long-term prognosis of renal function. These 
1 findings support that there is a reconsideration of "renalism," in which patients are

2 discouraged from having contrast studies because of fear of developing $\mathrm{CIN}$, even

3 though these studies are necessary. However, pre-existing chronic kidney disease is

4 the strongest patient-related risk factor for long-term renal prognosis, regardless of

5 the occurrence of $\mathrm{CIN}$.

6 We also found that in coronary angiography, a history of cardiovascular disease was

7 associated with long-term renal prognosis. Most patients with cardiovascular disease

8 undergo coronary angiography. Therefore, cardiac function assessment of prior to

9 coronary angiography is extremely important. In this study, saline administration

10 before and after angiography or the amount of contrast media used did not lower the

11 risk of $\mathrm{CIN}$, but this may be due to the small sample size.

12 Only one case of cholesterol crystal embolism was found on coronary angiography in

13 the current study. Cholesterol crystal embolism causes systemic organ embolism due

14 to the dissemination of cholesterol crystals caused by the continuous disintegration of

15 atherosclerotic foci in the walls of large vessels such as the aorta. Thus, it has poor

16 prognosis. The general population has an approximately $0.06 \%$ In probability of 
1 cholesterol crystal embolism after cardiac catheterization [18]. The subjects of the

2 present study were patients with pre-existing renal dysfunction, and the percentage

3 of occurrence of cholesterol crystal embolism in this study cannot be simply

4 compared with that of previous reports. A recent approach to coronary angiography

5 is mainly the radial artery, and the occurrence of cholesterol crystal embolism is

6 expected to be lower than that in the past. However, when renal function deteriorates

7 after coronary angiography, it is necessary to pay attention not only to changes in

8 serum creatinine, but also to the eosinophil count and lower limb symptoms.

9 This study has some limitations. First, the sample size was small, and thus, the study

10 findings may have limited generalizability. Second, this was a single-center study,

11 limiting the external validity of the findings. Third, it was not possible to accurately

12 determine whether the preoperative administration of serum saline was ineffective

13 because the use of serum saline was randomly assigned by the attending physician's

14 judgment. A larger clinical study is needed in the future. 
$1 \mathrm{CIN}$ is not a risk factor of long-term renal prognosis after coronary angiography or

2 contrast-enhanced CT scans. Pre-existing renal dysfunction does not increase the

3 risk of $\mathrm{CIN}$, even in patients with an eGFR $<30 \mathrm{ml} / \mathrm{min} / 1.73 \mathrm{~m}^{2}$. These findings will

4 provide a help that patients with kidney disease who need contrast-enhanced testing

5 should be tested appropriately.

6

\section{$7 \quad$ Availability of data and materials}

8 The datasets generated and/or analysed during the current study are not publicly

9 available due to limitations of ethical approval involving the patient data and

10 anonymity but are available from the corresponding author on reasonable request.

\section{Abbreviations}

13 CIN: Contrast-induced nephropathy

14 CT: Computed tomography

15 eGFR: estimated glomerular filtration rate 


\section{References}

2 1) B J Barrett. Contrast nephrotoxicity. Am Soc Nephrol. 1994 Aug;5(2):125-37.

3 2) Taliercio CP, Vlietstra RE, Fisher LD, Burnett JC: Risks for renal dysfunction with

4 cardiac angiography. Ann Intern Med 104: 501-504, 1986

5 3) Rudnick M, Tumlin J: Pathogenesis, clinical features, and diagnosis of

6 radiocontrast media-induced acute kidney in- jury (acute renal failure). In: Up to

7 Date, edited by Rose BD, UpToDate, Waltham, MA, 2007

8 4) Manske CL, Sprafka JM, Strony JT, Wang Y: Contrast nephropathy in azotemic

9 diabetic patients undergoing coronary angiography. Am J Med 89: 615-620, 1990

5) Barrett BJ, Parfrey PS, Vavasour HM, McDonald J, Kent G, Hefferton D, O'Dea F,

11 Stone E, Reddy R, McManamon PJ: Contrast nephropathy in patients with

12 impaired renal function: high versus low osmolar media. Kidney Int 41:1274-

6) Isaka $\mathrm{Y}$, Hayashi $\mathrm{H}$, Aonuma K, Horio M, Terada $\mathrm{Y}$, Doi K, Fujigaki $\mathrm{Y}$, Yasuda H, 
1 Murakami T, Yagyu Y, Joki N, Komatsu Y, Miyauchi T, Ito Y, Miyazawa R, Kanno

2 Y, Ogawa T, Hayashi H, Koshi E, Kosugi T, Yasuda Y; Japanese Society of

3 Nephrology, Japan Radiological Society, and Japanese Circulation Society Joint

$4 \quad$ Working Group. Guideline on the use of iodinated contrast media in patients with

$5 \quad$ kidney disease 2018. Clin Exp Nephrol. 2020 Jan;24(1):1-44.

6 7) Gruberg L, Mintz GS, Mehran R, Gangas G, Lansky AJ, Kent KM, Pichard AD,

7 Satler AF, Leon MB. The prognostic implications of further renal function

8 deterioration within $48 \mathrm{~h}$ of interventional coronary procedures in patients with pre-

9 existent chronic renal insufficiency. J Am Coll Cardiol. 2000 Nov 1;36(5):1542-8.

10 8) Roxana Mehran, George D Dangas, Steven D Weisbord. Contrast-Associated

11 Acute Kidney Injury. N Engl J Med. 2019 May 30;380(22):2146-2155

12 9) McDonald JS, McDonald RJ, Carter RE, KatBerg RW, Kallmes DF, Williamson

13 EE. Risk of intravenous contrast material-mediated acute kidney injury: a

14 propensity score-matched study stratified by baseline-estimated glomerular

15 filtration rate. Radiology $2014 ; 271: 65-73$ 
1 10) Jeremiah S Hinson, Michael R Ehmann, Derek M Fine, Elliot K Fishman,

2 Matthew F Toerper, Richard E Rothman, Eili Y Klein. Risk of Acute Kidney Injury

3 After Intravenous Contrast Media Administration. Ann Emerg Med. 2017

$4 \quad$ May;69(5):577-586.e4.

5 11) Jennifer S McDonald, Robert J McDonald, Eric E Williamson, David F Kallmes. Is

6 Intravenous Administration of lodixanol Associated with Increased Risk of Acute

$7 \quad$ Kidney Injury, Dialysis, or Mortality? A Propensity Score-adjusted Study.

8 Radiology. 2017 Nov;285(2):414-424.

9 12) Shu Min Tao, Xiang Kong, U Joseph Schoepf, Julian L Wichmann, Darby C

10 Shuler, Chang Sheng Zhou, Guang Ming Lu, Long Jiang Zhang. Acute kidney

11 injury in patients with nephrotic syndrome undergoing contrast-enhanced CT for

12 suspected venous thromboembolism: a propensity score-matched retrospective

13 cohort study. Eur Radiol 2018 Apr;28(4):1585-1593.

14 13) McDonald JS, Leake CB, McDonald RJ, et al. Acute kidney injury after

15 intravenous versus intra-arterial contrast material administration in a paired cohort.

$16 \quad$ Invest Radiol 2016; 51: 804-9. 
1 14) McDonald RJ, McDonald JS, Bida JP, et al. Intravenous contrast material-

2 induced nephropathy: causal or coincident phenomenon? Radiology 2013; 267:

$3 \quad 106-18$.

4 15) McDonald RJ, McDonald JS, Carter RE, et al. Intravenous contrast material

5 exposure is not an independent risk factor for dialysis or mortality. Radiology 2014;

$6 \quad 273: 714-25$.

7 16) Bruce RJ, Djamali A, Shinki K, Michel SJ, Fine JP, Pozniak MA. Background

8 fluctuation of kidney function versus contrast- induced nephrotoxicity. AJR Am J

$9 \quad$ Roentgenol 2009;192:711-8.

10 17) Goulden R, Rowe BH, Abrahamowicz M, Strumpf E, Tamblyn R. Association of

11 Intravenous Radiocontrast With Kidney Function: A Regression Discontinuity

12 Analysis. JAMA Intern Med. 2021 Apr 5:e210916.

13 18) Johnson LW, Esente $P$, Giambartolomei $A$, et al: Peripheral vascular

14 complications of coronary angioplasty by the femoral and brachial techniques.

15 Cathet Cardiovasc Diagn 3: 165-172, 1994 


\section{Acknowledgement}

2 We would like to thank Editage (www.editage.com) for English language editing.

3

\section{$4 \quad$ Funding}

5 None

6

\section{Author information}

$8 \quad$ Affiliations

9 1. Kidney Disease and Transplant Center, Shonan Kamakura General Hospital, 1370-1, Okamoto, Kamakura, Kanagawa, 247-8533, Japan

11 Hidekazu Moriya, Yasuhiro Mochida, Kunihiro Ishioka, Machiko Oka, Kyoko

12 Maesato, Mizuki Yamano, Hiroyuki Suzuki, Takayasu Ohtake, Sumi Hidaka, and

13 Shuzo Kobayashi

14 Contributions

$15 \mathrm{HM}, \mathrm{YM}, \mathrm{KI}, \mathrm{MO}, \mathrm{KM}, \mathrm{MY}, \mathrm{HS}, \mathrm{TO}, \mathrm{SH}$ collected data. HM analyzed data and wrote

16 the manuscript. HM and SK designed the study and critically reviewed the 
1 manuscript. All authors reviewed the manuscript. The author(s) read and approved

2 the final manuscript.

3 Corresponding author

4 Correspondence to Hidekazu Moriya

6 Ethics declarations

7 Ethics approval and consent to participate

8 This study was approved by the Tokushukai Group Ethics Committee (Registration

9 number: TGE00389-024) and was conducted according to the tenets of the Helsinki

10 Declaration. Informed consent was obtained from all patients.

11

\section{Consent for publication}

13 Not applicable.

14

15 Competing interests

16 The authors report no conflicts of interest.

17 


\section{Tables}

2

3 Table 1. Patient characteristics in the coronary angiography group $(n=142)$

4

\begin{tabular}{lr}
\hline Age (years) & $71.6 \pm 12.1$ \\
Sex (M/F) & $119 / 43$ \\
Smoking & $34(23.9)$ \\
Diabetes & $48(33.8)$ \\
Cardiovascular disease & $56(39.4)$ \\
Systolic blood pressure $(\mathrm{mmHg})$ & $123 \pm 14$ \\
Diastolic blood pressure $(\mathrm{mmHg})$ & $78 \pm 8$ \\
Blood urea nitrogen (mg/dl) & $28.6 \pm 5.6$ \\
Creatinine (mg/dl) & $1.96 \pm 0.71$ \\
Estimated glomerular filtration rate & $30.1 \pm 11.3$ \\
(ml/min/1.73m $\left.{ }^{2}\right)$ & \\
Albumin (g/dl) & $3.4 \pm 0.4$ \\
Hemoglobin (g/dl) & $13.4 \pm 2.3$ \\
Eosinophil count $(/ \mu \mathrm{l})$ & $234 \pm 22$ \\
Saline infusion & $45(31.7)$ \\
Volume of saline infused (ml) & $845 \pm 235$ \\
Volume of contrast media & $35 \pm 22$ \\
administered (ml) & \\
\hline Data are presented as the mean or $n$ \\
\hline
\end{tabular}

5 Data are presented as the mean or $\mathrm{n}(\%)$.

6 
1 Table 2. Changes in serum creatinine and outcomes at 2 years in patients

2 undergoing coronary angiography or contrast-enhanced computed tomography

3

4

\begin{tabular}{|c|c|c|c|c|c|c|c|c|c|c|}
\hline & \multicolumn{6}{|c|}{ Serum creatinine $(\mathrm{mg} / \mathrm{dl})$} & \multirow{2}{*}{$\begin{array}{c}\mathrm{CIN} \\
(\mathrm{n}(\%))\end{array}$} & \multirow{2}{*}{$\begin{array}{l}\text { CCE } \\
(n(\%))\end{array}$} & \multirow{2}{*}{$\begin{array}{c}\text { Worsening of } \\
\text { renal function }(n(\%))\end{array}$} & \multirow{2}{*}{$\begin{array}{l}\text { Death } \\
(\mathrm{n} /(\%))\end{array}$} \\
\hline & baseline & 3 days & 1 month & 3 months & 1 year & 2 years & & & & \\
\hline Angiography & $1.96 \pm 0.71$ & $2.00 \pm 0.66$ & $1.84 \pm 0.52$ & $1.89 \pm 0.59$ & $2.38 \pm 1.26$ & $2.58 \pm 1.30$ & $8(5.6)$ & $1(0.7)$ & $21(14.8)$ & $15(10.6)$ \\
\hline \multicolumn{11}{|l|}{$(n=142)$} \\
\hline$\overline{C T}$ & $1.72 \pm 0.74$ & $1.67 \pm 0.58$ & $1.36 \pm 0.55$ & $1.38 \pm 0.54$ & $1.69 \pm 0.60$ & $1.98 \pm 0.95$ & $11(4.1)$ & $0(0.0)$ & $17(6.3)$ & $19(7.1)$ \\
\hline$(n=268)$ & & & & & & & & & & \\
\hline
\end{tabular}

5 Abbreviations: CT, computed tomography; CIN, contrast-induced nephropathy; CCE, 6 cholesterol crystal embolism;

7 
1 Table 3. Relationship between the occurrence of $\mathrm{CIN}$ and renal function at contrast

2 media administration

3

4 A. Coronary angiography

\begin{tabular}{|c|c|c|c|}
\hline \multirow[b]{2}{*}{$\mathrm{n}=142$} & \multicolumn{2}{|c|}{$\begin{array}{l}\text { Renal function at contrast media administration } \\
\text { (estimated glomerular filtration rate [eGFR]) }\end{array}$} & \multirow[t]{2}{*}{$p$} \\
\hline & $\geqq 30 \mathrm{ml} / \mathrm{min} / 1.73 \mathrm{~m}^{2}$ & $<30 \mathrm{ml} / \mathrm{min} / 1.73 \mathrm{~m}^{2}$ & \\
\hline $\begin{array}{l}\text { Contrast- } \\
\text { induced }\end{array}$ & $3(2.1 \%)$ & $5(3.5 \%)$ & \\
\hline $\begin{array}{l}\text { nephropathy } \\
(\mathrm{CIN})(+)\end{array}$ & & & 0.441 \\
\hline $\operatorname{CIN}(-)$ & $69(48.6 \%)$ & $65(45.8 \%)$ & \\
\hline
\end{tabular}

5

6 B. Contrast-enhanced computed tomography

Renal function at contrast media administration

\begin{tabular}{lccc} 
& \multicolumn{2}{c}{$($ eGFR) } & $p$ \\
\cline { 2 - 3 } \multicolumn{1}{c}{$\mathrm{n}=268$} & $\geqq 30 \mathrm{ml} / \mathrm{min} / 1.73 \mathrm{~m}^{2}$ & $<30 \mathrm{ml} / \mathrm{min} / 1.73 \mathrm{~m}^{2}$ & \\
\hline $\mathrm{CIN}(+)$ & $5(1.9 \%)$ & $6(2.2 \%)$ & 0.457 \\
$\mathrm{CIN} \mathrm{(-)}$ & $146(54.5 \%)$ & $111(41.4 \%)$ & \\
\hline
\end{tabular}

7

8 
1 Table 4. Relationship between occurrence of contrast-induced nephropathy and

2 worsening of renal function at 2 years

3

4 A. Coronary angiography

\begin{tabular}{lccc}
\hline & \multicolumn{2}{c}{ Worsening of renal function } & \\
\cline { 2 - 3 } \multicolumn{1}{c}{$\mathrm{n}=142$} & $(+)$ & $(-)$ & \\
\hline Contrast- & $2(1.4 \%)$ & $6(4.2 \%)$ & \\
induced & & & 0.402 \\
nephropathy & & & \\
$(\mathrm{CIN})(+)$ & & & \\
$\mathrm{CIN}(-)$ & $19(13.4 \%)$ & $115(81.0 \%)$ & \\
\hline
\end{tabular}

5

$6 \quad$ B. Contrast-enhanced computed tomography

\begin{tabular}{lccc}
\hline & \multicolumn{2}{c}{ Worsening of renal function } & \multirow{2}{*}{$p$} \\
\cline { 2 - 3 } \multicolumn{1}{c}{$n=268$} & $(+)$ & $(-)$ & \\
\hline $\operatorname{CIN~}(+)$ & $2(0.7 \%)$ & $9(3.4 \%)$ & 0.099 \\
$\operatorname{CIN~(-)~}$ & $15(5.6 \%)$ & $242(90.4 \%)$ & \\
\hline
\end{tabular}

7

8

9

10 
1 Table 5. Factors associated with worsening renal function after coronary angiography

$2(n=142)$

3

\begin{tabular}{|c|c|c|c|c|}
\hline & & Number & $\begin{array}{l}\text { Worsened renal function } \\
\qquad(\mathrm{n}, \%)\end{array}$ & $p$ \\
\hline \multirow[t]{2}{*}{ Diabetes } & $(-)$ & 94 & $9(9.6)$ & \multirow{2}{*}{0.089} \\
\hline & $(+)$ & 48 & $12(25.0)$ & \\
\hline \multirow[t]{2}{*}{ Cardiovascular disease } & $(-)$ & 86 & $4(4.7)$ & \multirow{2}{*}{$<0.001$} \\
\hline & $(+)$ & 56 & $17(30.4)$ & \\
\hline \multirow[t]{2}{*}{ Diuretics } & $(-)$ & 114 & $15(13.2)$ & \multirow{2}{*}{0.269} \\
\hline & $(+)$ & 28 & $6(21.4)$ & \\
\hline Renin angiotensin system & $(-)$ & 54 & $9(16.7)$ & \multirow{3}{*}{0.621} \\
\hline \multirow[t]{2}{*}{ inhibitors } & & & & \\
\hline & $(+)$ & 88 & $12(13.6)$ & \\
\hline \multirow[t]{3}{*}{ Serum creatinine } & -1.5 & 78 & $1(1.3)] \dagger 7$ & \multirow{3}{*}{$<0.001$} \\
\hline & $1.5-2.5$ & 42 & $8(19.4)=$ & \\
\hline & $2.5-$ & 22 & $12(54.5)] \ddagger$ & \\
\hline \multirow{4}{*}{$\begin{array}{l}\text { Estimated glomerular } \\
\text { filtration rate } \\
\qquad\left(\mathrm{ml} / \mathrm{min} / 1.73 \mathrm{~m}^{2}\right)\end{array}$} & $45-$ & 34 & $1(2.9)$ & \multirow{4}{*}{$<0.001$} \\
\hline & & & & \\
\hline & $30-45$ & 66 & $6(9.1)$ & \\
\hline & -30 & 42 & $14(33.3)] \dagger$ & \\
\hline \multirow[t]{3}{*}{ Age } & $80-$ & 34 & 9 (26.5) & \multirow{3}{*}{0.053} \\
\hline & $60-80$ & 78 & $7(9.0)$ & \\
\hline & -60 & 30 & $5(16.7)$ & \\
\hline \multirow{4}{*}{$\begin{array}{l}\text { Volume of contrast media } \\
\text { administered } \\
\qquad(\mathrm{ml})\end{array}$} & -25 & 78 & $9(11.5)$ & \multirow{4}{*}{0.112} \\
\hline & & & & \\
\hline & $25-50$ & 44 & $6(13.6)$ & \\
\hline & $50-$ & 20 & $6(30.0 \%)$ & \\
\hline \multirow[t]{2}{*}{ Saline infusion } & $(-)$ & 97 & $15(15.5)$ & \multirow{2}{*}{0.739} \\
\hline & $(+)$ & 45 & $6(13.3)$ & \\
\hline
\end{tabular}

$4 \quad \dagger, p<0.001 ; \ddagger, p<0.01$ 
1 Table 6. Patient characteristics in the contrast-enhanced computed tomography

$2 \operatorname{group}(\mathrm{n}=268)$

3

\begin{tabular}{lr}
\hline Age (years) & $74.3 \pm 11.1$ \\
Sex (M/F) & $177 / 109$ \\
Smoking & $48(17.9)$ \\
Diabetes & $76(28.4 \%)$ \\
Cardiovascular disease & $42(15.7)$ \\
Systolic blood pressure (mmHg) & $132 \pm 12$ \\
Diastolic blood pressure (mmHg) & $82 \pm 8$ \\
Blood urea nitrogen (mg/dl) & $20.5 \pm 5.6$ \\
creatinine (mg/dl) & $1.72 \pm 0.74$ \\
Estimated glomerular filtration rate & $35.6 \pm 8.8$ \\
(ml/min/1.73m2) & \\
Albumin (g/dl) & $3.3 \pm 0.4$ \\
Hemoglobin ( $/$ dll) & $11.8 \pm 1.8$ \\
Eosinophil count $(/ \mathrm{Ml})$ & $379 \pm 65$ \\
Saline infusion ( $\mathrm{n}(\%)$ ) & $47(17.5)$ \\
Volume of saline infused (ml) & $568 \pm 40$ \\
Volume of contrast media & $82 \pm 34$ \\
administered (ml) & \\
\hline
\end{tabular}

4 Data are presented as the mean or $\mathrm{n}(\%)$.

5

6 
1 Table 7. Factors correlated with renal function deterioration in the contrast-enhanced

2 CT group $(\mathrm{n}=268)$

3

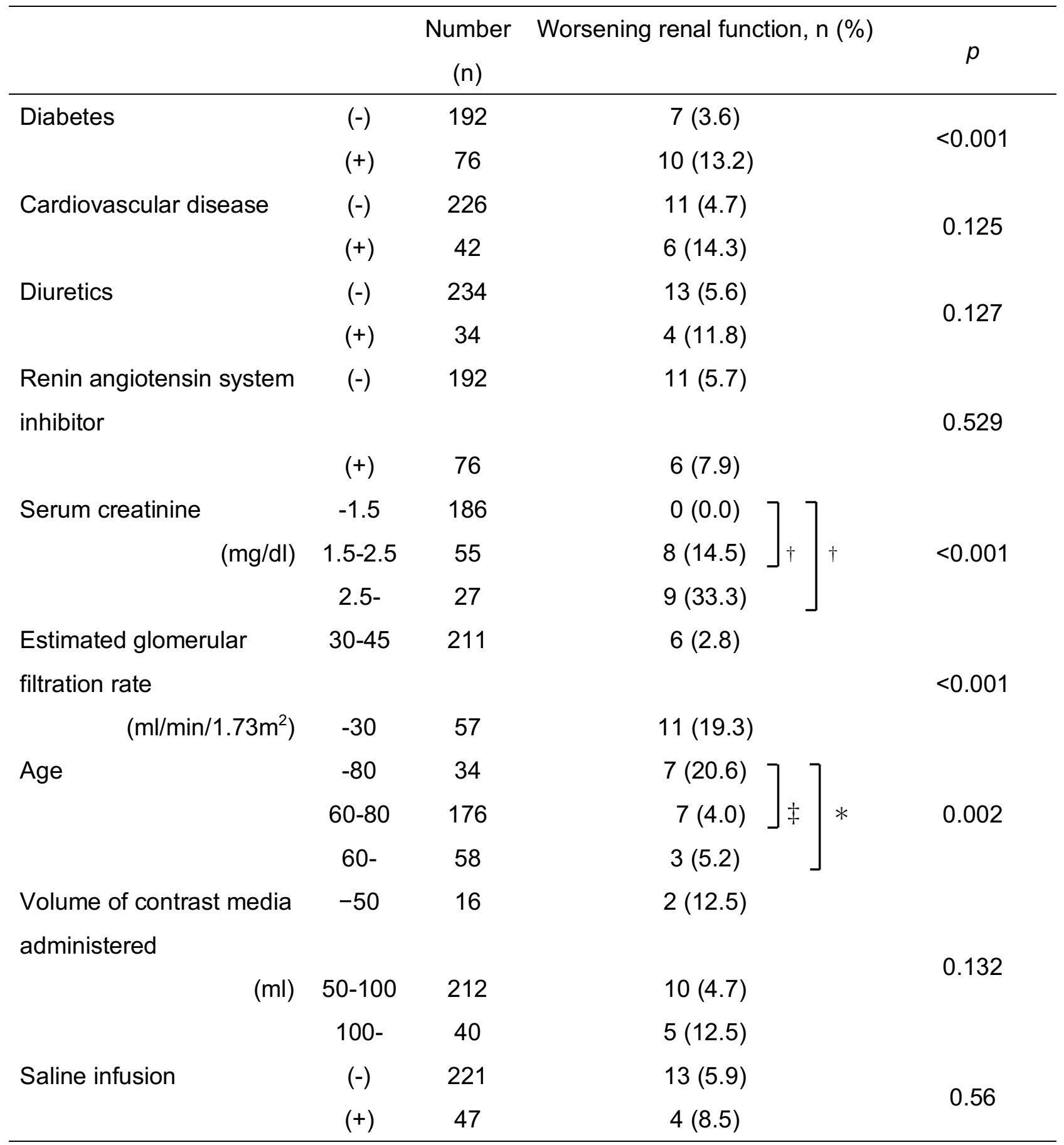

$4 \quad \dagger, p<0.001 ; \quad \ddagger, p<0.01 ; *, p<0.05$ 